\title{
High Magnetic Fields
}

Science and Technology 
This page is intentionally left blank

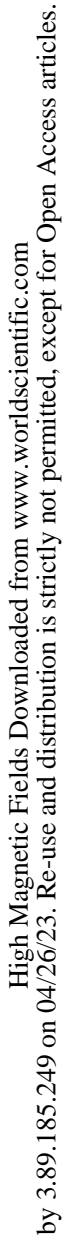




\section{High Magnetic Fields Science and Technology}

\section{Theory and Experiments I}

\section{Vol. 2}

\section{editors \\ Fritz Herlach}

Laboratorium voor Vaste-Stoffysika en Magnetisme,

Katholieke Universiteit Leuven, Belgium

\section{Noboru Miura}

Institute for Solid State Physics, University of Tokyo, Japan

\section{Noworld Scientific}




\section{Published by}

World Scientific Publishing Co. Pte. Ltd.

5 Toh Tuck Link, Singapore 596224

USA office: Suite 202, 1060 Main Street, River Edge, NJ 07661

UK office: 57 Shelton Street, Covent Garden, London WC2H 9HE

\section{British Library Cataloguing-in-Publication Data}

A catalogue record for this book is available from the British Library.

\section{HIGH MAGNETIC FIELDS: SCIENCE AND TECHNOLOGY (Vol. 2)}

Copyright $\odot 2003$ by World Scientific Publishing Co. Pte. Ltd.

All rights reserved. This book, or parts thereof, may not be reproduced in any form or by any means, electronic or mechanical, including photocopying, recording or any information storage and retrieval system now known or to be invented, without written permission from the Publisher.

For photocopying of material in this volume, please pay a copying fee through the Copyright Clearance Center, Inc., 222 Rosewood Drive, Danvers, MA 01923, USA. In this case permission to photocopy is not required from the publisher.

ISBN 981-238-975-X

ISBN 981-238-389-1 (Set) 


\section{CONTENTS}

Preface vii

Quantum Hall Effect: Theory

D. Yoshioka

Theory of Electron-Phonon Interactions in Semiconductors F.M. Peeters

Magneto-optics of Semiconductors

D. Heiman and C.H. Perry

Phase Coherence in Mesoscopic Systems at High Magnetic Fields

D. V. Khveshchenko and S. Washburn

Recent Studies of Quasi-Two-Dimensional Organic Metals Involving

High Magnetic Fields

J. Singleton and R.S. Edwards

Practical Low Temperature High Field Superconductors

S. Foner

Heavy Fermions

K. Sugiyama and Y. Ônuki

Low Dimensional Magnetic Systems

K. Katsumata

Ultrasonic and ESR Experiments in Pulsed Magnetic Fields up to $50 \mathrm{~T}$

B. Wolf, S. Zherlitsyn and B. Lüthi

High Magnetic Fields in Chemistry

U.E. Steiner and P. Gilch

Atoms and Molecules in Strong Magnetic Fields

P. Schmelcher and L.S. Cederbaum 
This page is intentionally left blank

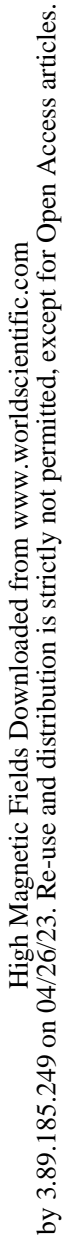




\section{PREFACE}

The magnetic field is a basic research tool in physics, with most applications in solidstate physics. Apart from the exciting aspect of advancing into uncharted territory where s. new effects are waiting to be discovered, higher fields provide both increased resolution and sensitivity. The Physics Nobel Prize for the discovery of the quantum fluid in high magnetic fields by Laughlin, Störmer and Tsui is one of the recent highlights. "Very high fields" are loosely defined as requiring special and some very large magnet laboratory facilities. Since the last comprehensive book on experiments with high magnetic fields was published in 1985 (Strong and Ultrastrong Magnetic Fields and Their Applications, ed. F. Herlach, Springer Topics in Applied Physics), very substantial progress has been made in magnet technology and experimental methods, and a wealth of experimental results has been accumulated. This is reflected in the size of the present survey, which consists of three volumes, one on magnet technology, facilities and experimental techniques, and two on experiments and theory of physics and related topics in high magnetic fields.

In magnet technology, $33 \mathrm{~T}$ water-cooled magnets and a $45 \mathrm{~T}$ hybrid magnet have become operational at the U.S. National High Magnetic Field Laboratory at Tallahassee, and the new Nijmegen magnet laboratory is nearing completion. Several new laboratories with pulsed magnets have been established, and existing laboratories have been upgraded and modernised. The latest development is the funding of the new pulsed field laboratory at Dresden where a 50 MJ capacitor bank will be built. The level of non-destructive "user" fields has been raised from 50 to $70 \mathrm{~T}$, and $80 \mathrm{~T}$ should become available soon, as the result of a European co-operative project. Several single-turn coil installations have been built at Tokyo and Berlin that provide fields up to $300 \mathrm{~T}$, and in electromagnetic compression it has recently become possible to generate $600 \mathrm{~T}$ reproducibly (at the University of Tokyo). These fields are now currently used for sophisticated experiments in a convenient laboratory environment. Fields up to $1000 \mathrm{~T}$ from explosive-driven flux compression have become available for experiments at Sarov (Russia) and Los Alamos (partner of NHMFL). For pulsed magnetic fields in particular, new experimental techniques have been developed with unprecedented resolution and sensitivity, enabling experiments that two decades ago would have been considered a remote dream.

The present volume begins with two chapters on the theory of electron interactions in semiconductors, followed by a chapter on related experiments. The chapter on mesoscopic systems deals with aspects of artificially made microstructures. The fabrication of microstructures with dimensionality reduced down to zero (e.g. quantum dots) is notably one of the general trends in modern semiconductor physics. Organic conductors can be thought of as self-organised low-dimensional structures where the excellent quality of the samples derives from natural growth, covering a plethora of quantum phenomena that can be followed into the range of the highest fields. Superconductivity is another topic where research in high magnetic fields is essential (high temperature superconductors are covered in Volume 3). Two chapters are devoted to magnetic interactions. This has a long tradition in high-field research as the strength of these interactions extends into the $100 \mathrm{~T}$ range. This field of research has been largely expanded by advances in synthesizing new materials with properties tailored to allow detailed theoretical analysis. The newly developed 
technique of ultrasonic measurements has been applied mostly to magnetic systems so far; it is anticipated that this will be useful in other areas of solid-state physics. The final two chapters cover topics that are relatively new in high-field research, with promising prospects for further development: chemistry and single atoms and molecules.

Each chapter provides a tutorial introduction followed by an in-depth discussion of recent experiments and theory with a view to future developments, as well as a comprehensive bibliography. We hope that these volumes will be useful as a stimulus as well as a reference tool for researchers and engineers working with high magnetic fields, and for students who want to become familiar with this field of research. 